\title{
Uma nova generalização para as séries de fibonacci
}

\section{Another type of generalized fibonacci series}

\author{
Gil Bazanini ${ }^{1}$; Júlio Pureza²
}

\section{Resumo}

A sequência de Fibonacci, importante no estudo da natureza e nas artes, é discutida neste trabalho. É proposta uma generalização da série de Fibonacci, através do emprego de um coeficiente na relação de recorrência da série. Segundo critérios de convergência usuais, demonstra-se que tais séries são divergentes quando o coeficiente é a raiz quadrada de um número positivo. No entanto, a relação entre dois termos consecutivos da série é convergente, sendo o coeficiente um número real.

Palavras-chave: Fibonacci. Séries. Convergência.

\begin{abstract}
The Fibonacci sequence, with many applications and occurrences in nature and arts is discussed in the present work. It is considered a generalization of the Fibonacci series by the introduction of a real coefficient in the recurrence relation. The analysis shows the divergence of the generalized series when the coefficient is the square root of a positive number, although the relation between two consecutive terms converges to a finite number when the coefficient is a real number.
\end{abstract}

Key words: Fibonacci. Series. Convergence.

\section{Introduction}

The Fibonacci sequence, found by the mathematician Leonardo Pisano in 1202, and so named by Edouard Lucas in 1877 (HUNTLEY, 1970), has been related to many occurrences in nature (BASIN, 1963), such as the growth of the nautilus shell, the packing of sunflower seeds and pineapple spirals. This sequence is also present in Geometry and Art (HUNTER, 1963; HUNTLEY, 1964; RAPHAEL, 1970).

The Fibonacci sequence is very well illustrated by the rabbit problem, proposed by Pisano, and described by Agostini (1987): how many pairs of rabbits will be produced, beginning with a single pair (male and female), considering that every month each pair bears a new pair, which becomes productive from the second month on? The answer is the Fibonacci sequence $(0,1,1,2,3,5,8,13, \ldots)$, that obeys the recurrence relation:

$$
F(n+2)=F(n)+F(n+1)
$$

where $F(0)=0 ; F(1)=1 ; n>1$

\footnotetext{
${ }^{1}$ Dr. in Mechanical Engineering. Santa Catarina State University-Udesc. E-mail: dem2gb@joinville.udesc.br

${ }^{2}$ Dr. in Physics. Santa Catarina State University-Udesc. E-mail: pureza@joinville.udesc.br
} 
Each term is obtained by the sum of the preceding two. As the sequence proceeds, the ratio between two consecutive terms approaches to the golden ratio ø, as seen in Dunlap (1997):

$$
\phi=\frac{1+\sqrt{5}}{2}
$$

Which is the positive root of the characteristic equation (HUNTLEY, 1970):

$$
x^{2}-x-1=0
$$

For the Fibonacci series, the general term is given by the Binet's Formula (HUNTLEY, 1970):

$$
F(n)=\frac{1}{\sqrt{5}}\left[\left(\frac{1+\sqrt{5}}{2}\right)^{n}-\left(\frac{1-\sqrt{5}}{2}\right)^{n}\right]
$$

Although the ratio of two consecutive Fibonacci terms converges to $\varnothing$, the Fibonacci series is divergent. This can be proved using known necessary conditions for convergence, seen in classical mathematical books as Piskunov (1964) and Poussin (1940). In the next section, these necessary conditions for convergence of numerical series will be applied to the generalized series.

\section{The Generalized Fibonacci Series}

According to Palladino and Ferreira (2000), the Fibonacci sequence may be generalized introducing a coefficient in one of the terms of the recurrence relation:

$$
F(n+2)=F(n)+\delta F(n+1)
$$

where $\delta$ is taken to be the square root of a positive integer $k$. The characteristic equation becomes:

$$
x^{2}-\delta x-1=0
$$

$F(n)=\frac{1}{\sqrt{5}}\left[\left(\frac{\sqrt{k}+\sqrt{4+k}}{2}\right)^{n}-\left(\frac{\sqrt{k}-\sqrt{4+k}}{2}\right)^{n}\right]$

where $k>1$ and $\mathrm{n}=0,1,2, \ldots$. The general term of this generalized sequence is, for large $n$ (the second term takes the difference between the square roots, while the first term takes the addition of both. So the second term becomes negligible when compared to the first one, as $n$ becomes large):

$F(n)=\frac{1}{\sqrt{5}}\left[\left(\frac{\sqrt{k}+\sqrt{4+k}}{2}\right)^{n}\right]$

that diverges as $n$ goes to infinity. This divergence may also be proved by using the D'Alembert's test,

$\left.\lim _{n \rightarrow \infty} \frac{F(n+1)}{F(n)}=\lim _{n \rightarrow \infty}\left[\left(\frac{\sqrt{k}+\sqrt{4+k}}{2}\right)^{n+1}-\left(\frac{\sqrt{k}-\sqrt{4+k}}{2}\right)^{n+1}\right]\right]=\frac{\sqrt{k}+\sqrt{4+k}}{2}>1$

$\delta=2 \sinh \alpha$

Since the limit is greater than one, the series diverges. This series can be set in another form, as proposed by Palladino and Ferreira (2000), where and $\alpha$ is a real number. If $F(0)=0$ and $F(1)=1$, the general term becomes

$$
F(n)=\frac{1}{\sqrt{5}}\left[\left(e^{\alpha}\right)^{n}-\left(-e^{-\alpha}\right)^{n}\right]
$$

And now, for the extended case, where the seed values $F(0)$ and $F(1)$ are non-fixed (PALLADINO; FERREIRA, 2000),

$$
\begin{gathered}
F(n)=\frac{1}{\sqrt{5}} 2 \sinh (n \alpha), n \text { even } \\
=\frac{1}{\sqrt{5}} 2 \cosh (n \alpha), n \text { odd }
\end{gathered}
$$

and the general term of the sequence is given by: 
$F(n)=F(0) \cosh (n \alpha)+\frac{2 F(1)-2 F(0) \sinh (\alpha)}{2 \cosh (\alpha)} \sinh (n \alpha), n$ even

$=\frac{2 F(1)-2 F(0) \sinh (\alpha)}{2 \cosh (\alpha)} \cosh (n \alpha)+F(0) \sinh (n \alpha), n$ odd

\section{Results}

Vorobiev (1973) used the linear combination procedure to obtain the general term for the usual Fibonacci series. That will be done now for the generalized Fibonacci series. Another generalization of the series can be done by setting the coefficient $\delta$ as a real number. In this case, the general term is the linear combination of the roots of the characteristic equation (5):

$$
F(n)=A x_{1}^{n}+B x_{2}^{n}
$$

where $A$ and $B$ are functions of the seed values $F(0)$ and $F(1)$. Considering the choice $F(0)=F(1)=1$, results:

$$
F(n)=\frac{1-x_{2}}{x_{1}-x_{2}} x_{1}^{n-1}+\frac{x_{1}-1}{x_{1}-x_{2}} x_{2}^{n-1}
$$

where

$$
x_{1}=\frac{\delta+\sqrt{4+\delta^{2}}}{2} \quad x_{2}=\frac{\delta-\sqrt{4+\delta^{2}}}{2}
$$

In fact, the ratio of two consecutive terms of the generalized series is given by

$$
\frac{F(n+1)}{F(n)}=\frac{\left(1-x_{2}\right) x_{1}^{n}+\left(x_{1}-1\right) x_{2}^{n}}{\left(1-x_{2}\right) x_{1}^{n-1}+\left(x_{1}-1\right) x_{2}^{n-1}}
$$

Figures 1 to 7 relate the ratio $(F(n+1) / F(n))$ to the index $n$ of the sequence. It can be seen that this ratio converges to a real number that depends on the coefficient coefficient $\delta$ and some interesting shapes can be found depending on the sing of the coefficient. Also, as the coefficient goes larger the ratio goes to the same value of the coefficient, leading to the relation shown in figure 8 .

As a matter of fact, the ratio $(F(n+1) / F(n))$ leads to a limit similar to the golden ratio $\varnothing$. The D'Alembert's test gives for the generalized sequence the limit,

$\phi_{k}=\frac{\sqrt{k}+\sqrt{4+k}}{2}$

where the index $k$ is defined in section 2 and characterizes the generalized Fibonacci sequence. This limit conforms to agree with the Figures 1 to 7 and the relation shown in Figure 8.

\section{Conclusions}
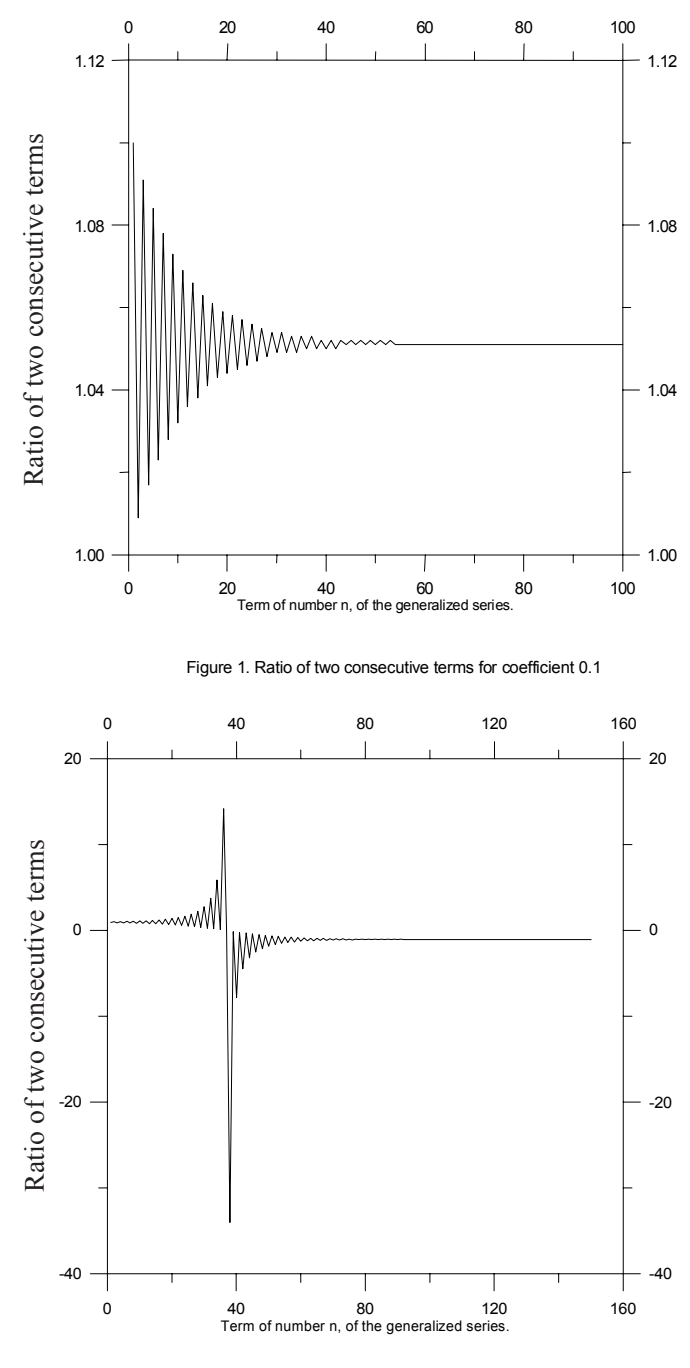

Figure 2. Ratio of two consecutive terms for coefficient -0.1 
Bazanini, G.; Pureza, J.

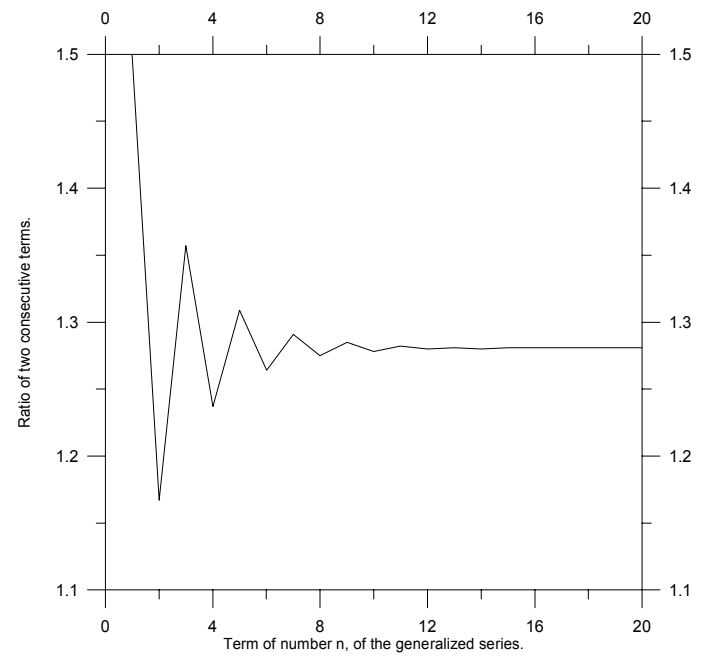

Figure 3. Ratio of two consecutive terms for coefficient 0.5

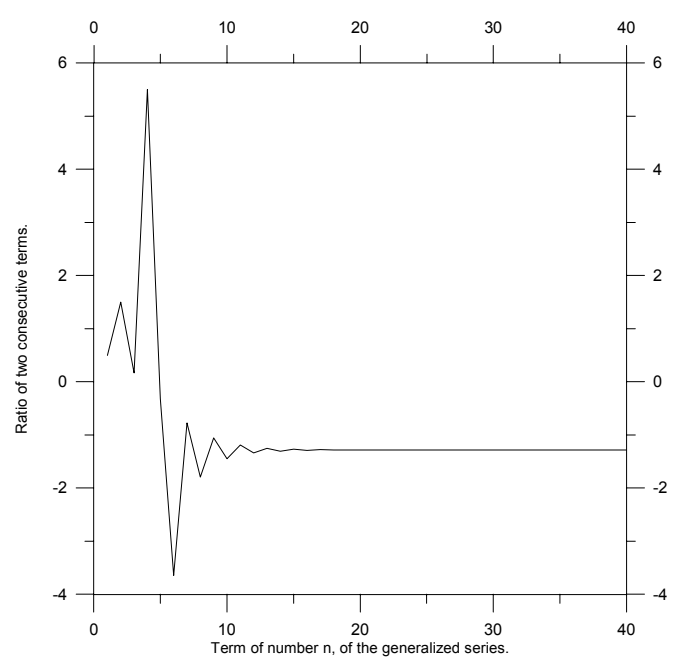

Figure 4. Ratio of two consecutive terms for coefficient -0.5

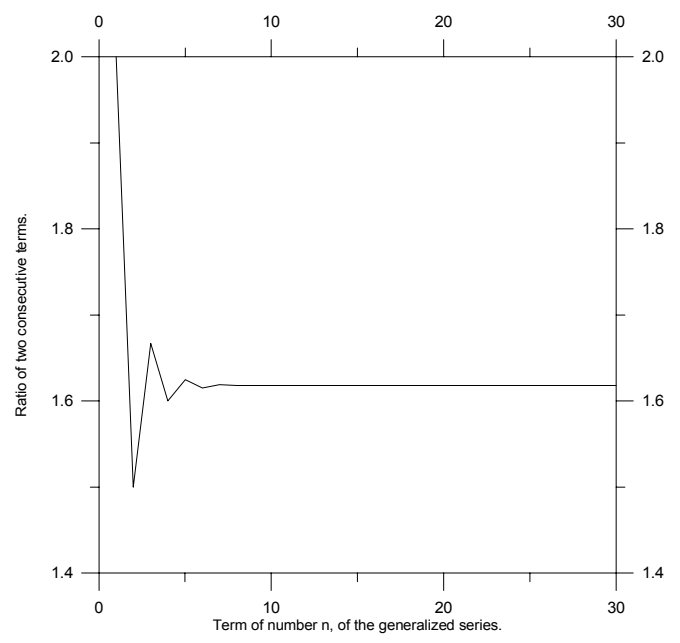

Figure 5. Ratio of two consecutive terms for coefficient 1

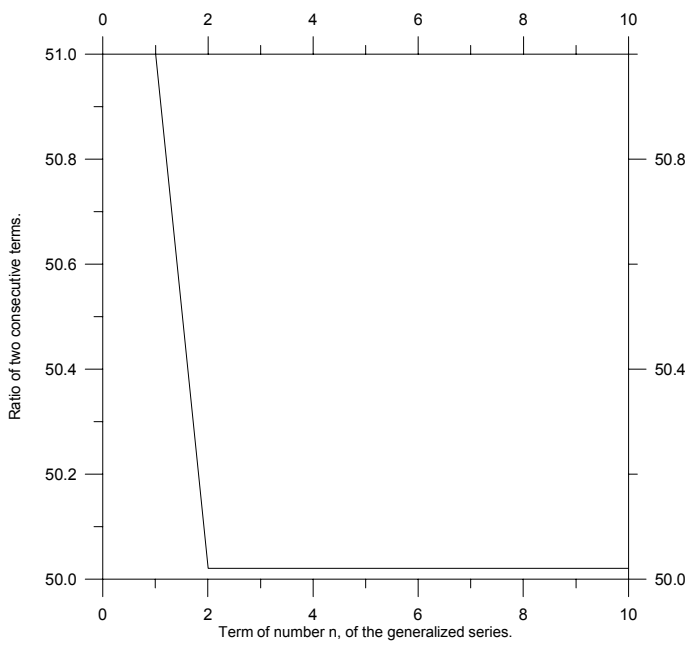

Figure 6. Ratio of two consecutive terms for coefficient 50

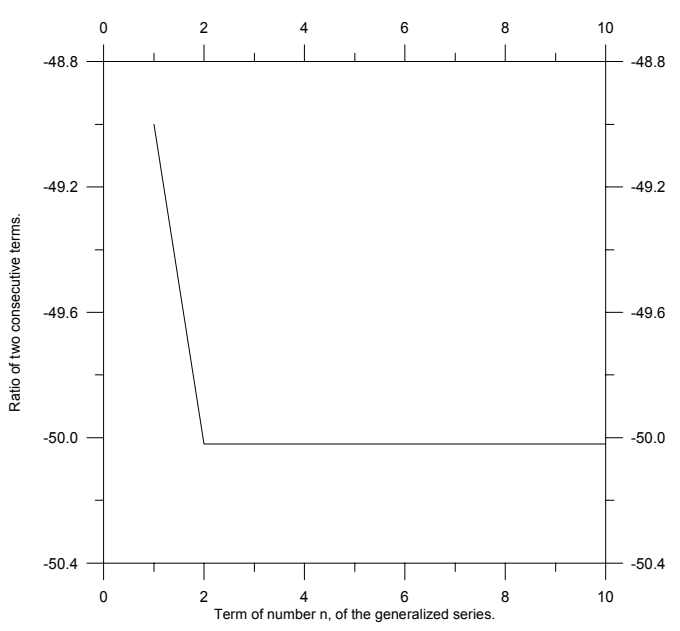

Figure 7. Ratio of two consecutive terms for coefficient -50

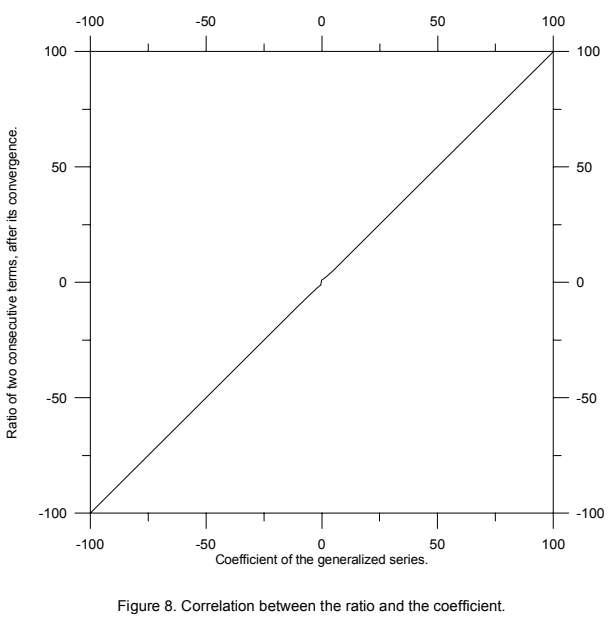


As seen in the present work, it is possible to generalize the Fibonacci series through the use of a coefficient $\delta$ in one of the terms of the recurrence relation, which is set as the unity for the usual Fibonacci series, that becomes then a particular case of the generalized one.

It was also demonstrated that, although the generalized series diverges as $n$ goes to infinity, the ratio of two consecutive terms converges. The smaller is the coefficient, slower is the convergence of the sequence. Also, for greater values of the coefficient, closer is its value to the ratio of two consecutive terms, after the convergence is aimed. This leads to the correlation seen in Equation (17) and Figure 8.

The convergence value of the ratio of two consecutive terms, as seen in Figures 1 to 8, resembles an attractor, as described in Alligood, Sauer and Yorke (1996) and Ricieri (1992). In fact, attractors were already obtained by Caruso and Marotta (2000), when working with the complex numbers in the generalization of the Fibonacci series, named as "The Vibonacci Series".

\section{References}

AGOSTINI, F. Juegos de logica y matematicas. Madrid: Edicones Pirámide, 1987.

ALLIGOOD, K. T.; SAUER, T. D.; YORKE, J. A. Chaos: an introdution to dynamical systems. New York: Springer Verlag, 1996.

BASIN, S. L.. The Fibonacci sequence as it appears in nature. The Fibonacci Quarterly, Santa Clara, v.1, p.5356, 1963.

CARUSO, H. A.; MAROTTA, S. M. Sequences of Complex Numbers Resembling the Fibonacci Series. Revista de Ciências Exatas e Naturais, Guarapuava, v.2, n.1, p.49-59, dez., 2000.

DUNLAP, R. A. The Golden Ratio and Fibonacci Numbers. New Jersey:: World Scientific Press, 1997. $162 \mathrm{p}$.

HUNTER, J. A. H. Triangle Inscribed in a Rectangle. The Fibonacci Quarterly, Santa Clara, v.1, p.66, 1963.

HUNTLEY, H. E. The Divine Proportion: a study in mathematical beauty. New York: Dover, 1970.

HUNTLEY, H. E. Fibonacci Geometry. The Fibonacci Quarterly, Santa Clara, v.2, p.104, 1964.

PALLADINO, B. E.; FERREIRA, P. L. A New Type of Generalized Fibonacci Sequences. São Paulo: UNESP, 2000.

PISKUNOV, N. S. Differential and Integral Calculus. Moscow: Mir Pub, 1964.

POUSSIN, C. L. V. Cours D'Analyse Infinitésimale. New York: Dover, 1940.

RAPHAEL, B. L. Some results in trigonometry. The Fibonacci Quarterly, Santa Clara, v.8, p.371, 1970.

RICIERI, A. P. Fractais e Caos: a matemática de hoje. São Paulo: Prandiano, 1992. 131p.

VOROBIEV, N. Caractères de divisibilité-suite de fibonacci. Moscou: Ed. Mir, 1973.214p. 